\title{
Information behaviour of recent Chinese immigrants in Auckland, New Zealand
}

\author{
Myrna Machet ${ }^{\prime}$ \\ Department of Information Science, UNISA, Pretoria, 0003, South Africa \\ myrna.machet@gmail.com \\ Kasturi Sandra Govender ${ }^{2}$ \\ Mount Isa City Library, QLD, Australia \\ sandrag@mountisa.qld.gov.au
}

\begin{abstract}
Received 22 February 2012
Accepted 25 May 2012

Public library services in New Zealand are being re-examined in light of the developments in ICT and an increasingly multicultural population. The research question investigated was "Can an internet portal on a public library website be used to meet the information needs of new Chinese Mandarin immigrants to the Auckland region of New Zealand?" In an attempt to effectively answer the research question and sub-questions a literature survey was carried out focusing on two aspects relevant to the study: immigration theory and information behaviour (IB). Thirty Chinese Mandarin speaking recent migrants to the Auckland region of New Zealand were interviewed in-depth to determine their IB and resources used. The findings indicate that respondents were in need of everyday survival information. The findings suggest that a more coordinated approach to information provision, for example through a library web portal, will assist respondents in their search for information relating to their initial settlement.
\end{abstract}

Keywords: Digital libraries, information behaviour, migrants, multicultural library web services, public libraries, user studies

\section{Introduction}

In the early 1980s there was a Maori renaissance and New Zealand adopted a bicultural strategy. Some institutions, such as public libraries, made a concerted effort to implement this bicultural approach by, for example, using bicultural signage, developing special Maori collections, using Maori subject headings and so on. However, immigration is making New Zealand increasingly multicultural and it is becoming necessary for public libraries to broaden their approach from that of biculturalism to multiculturalism. Cities such as Auckland, Christchurch and Manukau attracted an unprecedented large concentration of ethnic minorities such as Asians, Africans and other, smaller ethic groups (Statistics New Zealand 20I0).

In addition, the technological revolution and developments in ICT are posing a challenge and creating new opportunities for public libraries. Public libraries in New Zealand today are being subjected to two challenges: the expanding use of the internet and changing demographics. Technology in general and the internet in particular offer new possibilities for extending existing multicultural library services in public libraries. To adequately perform the task of serving multicultural populations, public libraries must identify ways of assessing the effectiveness of their activities and evaluate their changing roles and responsibilities in light of these changes. The information environment, particularly the digital information environment, requires a re-conceptualization of the information creation, dissemination and usage processes to cater for the information needs of multicultural populations.

Although studies on the needs of new immigrants have been done (Caidi 2008; Chatman 1996 \& 1999; Childers 1975; Fisher, Durance \& Hinton 2004; Kirkland 2010; Srinivasen \& Pyati 2007), little research exists on the library services needed by such populations or on the use of such services to meet their information needs. In particular, little research has been conducted on whether a library webpage can be used to meet these needs.

The problem being investigated in this article is the information behaviour of new Chinese immigrants and the feasibility of setting up a multicultural public library website to address the information needs of new immigrants in the Auckland region of New Zealand.

I. Myrna Machet (PhD), Department of Information Science, University of South Africa.

2. Kasturi Sandra Govender is a Senior Librarian at Mount Isa City Library, QLD, Australia. 


\section{Research question}

There are two research questions discussed in this article:

I. What is the information behaviour of new Chinese immigrants to New Zealand?

2. What is the role of the public library in meeting the needs of these new Chinese immigrants?

\section{Literature overview}

In the following section the literature reviewed will be briefly outlined.

\subsection{Immigration}

Immigration necessitates adapting to new economic, social, and cultural conditions. The immigration process is dynamic and can best be understood as a process with various stages. A newcomer in the first stage is likely to have pressing needs for information that will contribute to his/her survival. As the immigrant becomes accustomed to the adopted country, finds his/her place in society and contributes economically and socially to its welfare, different needs may arise in the intermediary stage such as the need for belonging more fully and becoming an active citizen, for example, political participation, civic duties and cultural celebrations (Papillon 2002:4-5). The implications are that immigrants' information needs tend to become more diverse and individual in the last stage, as established migrants. Learning to overcome many systematic barriers to equal participation can be viewed as a common process for all immigrants at this stage. New immigrants also have particular social, cultural and work environments.

New immigrants may not have a fully developed social network upon their arrival into their host or adopted country, or may have one that is not adequate in size, density and strength to help facilitate their transition. As immigrants become established over a period of time, their social networks' characteristics may evolve and change, reflecting their interactions with the environment. Moreover, differences between the first, second and third generations of immigrants may widen as the first generation may be at increased risk of lower occupational status, higher underemployment, higher poverty and so on. First generation immigrants may also be more inclined to maintain transnational relationships in the form of friendships and kin networks with people from their country of origin (Papillon 2002:3-4).

New migrants need the following information on arrival: language (information about training, translation, and interpretation services), employment information (including job-searching skills and special services to foreign-trained professionals), housing information, information about making connections in the community (including connections to professional associations, volunteer opportunities, mentoring and community organisations), information about the new country's culture and orientation to life. Later in the settlement process migrants need health, employment and educational information as well as political information and current events (news about country of origin as well their adopted country), language-learning information (including information about ESL programmes and materials), information about identity construction (becoming a New Zealander, for example) and cultural and religious events (Caidi 2008).

Understanding the stages of immigrants' adaptation to the host country, their differing environments and the situations they face can elicit findings about how and whom they approach in order to find information to solve their everyday problems and the role of the public library in meeting these needs. There may be barriers to the use of public libraries and services by new migrants. These may include: i) institutional barriers, for example, opening hours, availability of library services, staff attitudes, rules and regulations; ii) personal and social barriers, for example, basic literacy skills, low income and low self esteem; iii) environmental barriers, for example, physical access, remote areas, and isolation and iv) perception barriers, for example a sense of isolation, educational disadvantage, relevance of libraries to one's need, and lack of knowledge about existing facilities and services (Hare 2009:5). It is important to determine whether the above barriers impact on migrants and their willingness and ability to source information from the public library to meet their information needs.

The traditional function of the public library system is to provide services and resources in a variety of media to serve the educational, informational, recreational and cultural needs of its community irrespective of age. In the digital age public libraries are democratizing institutions that allow free access to information that may otherwise be available only to the privileged. The LIANZA report on the future of public libraries in New Zealand (2006:14-15) states that 'demographic changes will continue to impact on public libraries and test the planning capacity and the flexibility of the sector'. It highlights social changes such as migration and the changing ethnic mix and internal population flows leading to growing and declining communities.

\subsection{Multiculturalism and digital libraries}

Two of the main challenges faced by public libraries are multiculturalism as a result of increased immigration and ICT developments. Globalization has increased the exchange of goods and ideas between countries in all parts of the world. It 
is probably the strongest, international force for change in our society today. Srinivasen and Pyati (2007:1737) note that online environments provide a space for immigrant communities to articulate diverse and hybridized imaginations of home. The authors state further that this helps transcend the concept of globalisation and the apparent local/global contradiction in immigrant online behaviour. While local environments remain important, immigrant information behaviour is not merely confined to local contexts.

Global information environments are more and more ubiquitous. Digital libraries are institutions that have grown due to the rapid advancements in ICT. Thorhauge (2010:3) maintains that the need for strategies and the development of different models for the exploitation of knowledge resources vary from country to country and no one model can be termed the right one. The traditional public library is developing into a learning and inclusive community centre with digital service as part of the programme. He (2010:4) asserts further that the organization of digital libraries will depend on how traditional the library structure is, how the country's educational system is organized, how the information infrastructure is organized as well as technological and socio-cultural aspects. For example, in some countries free and equal access to information as a public service is a longstanding tradition, whereas in other countries this is not the case.

In the knowledge society, libraries' challenge is to create structured access to the mass of information which increases exponentially and is much bigger than the library's own collection. In addressing its challenges New Zealand public libraries need to look at new options offered by ICT such as multicultural websites. Globalisation has made countries more multicultural and less homogeneous, especially in countries with high levels of immigration such as Australia, Canada, the USA and New Zealand. ICT has provided challenges as well as opportunities for public libraries. Public libraries in some countries, such as Australia and Canada, are using freely available internet technologies to create and maintain multicultural library websites. New Zealand has a bicultural approach to public library service provision and has made limited use of library websites thus far.

Many public libraries provide materials in other languages besides the official language(s) of the country. However, budget limitations and difficulties involved in acquiring materials in other languages prevent most libraries from developing significant collections. Since most libraries in developed countries now have internet access and provide web-based resources for their patrons, they are able to provide access to significant online collections that are of interest to people who speak other languages. Furthermore, the current level of multicultural e-content on the web has exponentially increased the potential for libraries to provide multicultural library services and access to information and e-content in other languages. One of the main roles for libraries in providing this type of service is to evaluate and provide links to an appropriate selection of e-content. Lo Bianco, Cunningham and McCombe (2010:6) suggest that through the internet multicultural websites for culturally and linguistically diverse migrant communities can be created.

The ever-changing landscape of the information environment presents a diverse range of new digital technologies and information challenges. A recent addition is the introduction of Open Source Software (OSS) via the internet. It is important for information professionals to be informed of new and free software opportunities in order to leverage the relevant contextual benefit for the library communities served. Web based solutions in OSS include integrated library management systems (ILMS), library portals and portlets, digital libraries, institutional repositories, open archives harvesting, e-learning, content management, knowledge management, open URLs, social software for blogs, wikis, RSS, federated searching and so on. Some freely available basic (OSS) software that libraries may use include: I) Ubuntu, a solution for libraries who need to upgrade from outdated Windows 2) Firefox, an alternative for Internet Explorer that offers safer browsing and many plug-ins are available 3) Open Office, which is similar to Windows Office but allows for editing capabilities 4) Thunderbird or Gmail for e-mails with free add-ons and 4) Songbird, which is used to play audio and video files (Breeding 2009:22-25). The benefit of OSS for libraries is that it can be adapted to meet the specific requirements of small language communities in a cost effective way using freely available internet software and cloud technology.

\subsection{Information behaviour (IB)}

There are different approaches to understanding human information behaviour, namely, the cognitive, social, socialcognitive and organizational approaches. The cognitive models are important in understanding the users' intrinsic motivation in the search process, whereas the social models are useful in understanding the user in his/her search for information using different sources. The cognitive models are therefore important in the design of information systems whereas social models are useful in understanding the user in his/her search for information using information systems.

Wilson's (1999) general model of IB views IB as an individualistic and problem solving process. The model incorporates features of other IB models, reflecting the various approaches such as elements of Belkin (I980); Dervin (1999); Kuhlthau (2005) (cognitive approaches); Chatman (1985, 1996 \& 1999); Pettigrew (I998 \& I999); Tuominen and Savolainen (1997) (social approaches), but places emphasis on the contextual and situational aspects of the user. This 
approach allows for flexibility in examining IB effectively. From a library perspective it is imperative to examine IB multidimensionally in order to design systems that will meet the information needs of users effectively and efficiently.

The cognitive approach emphasises that information seeking forms an important and integrated part of problem solving (Bates 1979; Belkin 1990; Belkin, Oddy \& Brooks, 1982; Dervin 1983; Dervin \& Foreman-Wernet 2003; Ellis 1989; Ingwersen 1992 \& 1996; Kuhlthau 1993). It affects the quality of a given task and its solution. Implicit in most of the studies is the assumption that the information seeker is an individual. The cognitive approach therefore seeks to illuminate the mental activity entailed in individuals as they seek and use information to resolve a particular problem.

The social approach focuses primarily on the study of the effect that social factors have on IB (Chatman 1985; Pettigrew 1999; 2000; Tuominen \& Savolainen 1997). This approach assumes that the study of IB cannot be considered in terms of isolated individuals or outside a specific context, but should take into account the social contexts and conditions, interactions and discourse through which human-information interaction occurs. This approach views the person as someone who lives and acts in a certain context, rather than as a user of information systems and services.

Most of the earlier models, for example Dervin (1983), represent IB as a sequential progression entailing the following sequence: the individual experiences an information need; goes out to seek information; finds it and solves the need for information. However, Wilson (1999:267) remarks that 'feedback loops must exist within all models, since progression towards a goal is hardly ever unproblematic'. This is similar to what Dervin (1992:70) and Pettigrew (1999) have observed, namely that information seekers do not follow a linear path nor is it always the optimal route. The implication is that the order of information seeking tasks may be reversed or convoluted and includes dead-ends, changes of directions, iterations, abandonment and beginning again.

The convergence of information and communication technologies is the major impetus driving the development of the information society. The most important feature of this is the large amount of information accessible instantly anywhere. According to Lievrouw (200I) cited in Meyer (2009:6) information technology not only forms an integral part of information contexts but also makes them more complex. The argument that information and communication technologies can become either bridges or barriers seems to be highly relevant today. A global view of ICT is that it connects one with one's own culture and with other cultures. It empowers one through access to information and education. ICT is an important means of providing access to information and communication and in doing so creates borderless societies. The discussion following is an example of how ICT can be incorporated into the understanding of IB.

3.4 Role of virtual information communities in meeting the needs of the user within specific contexts Virtual communities according to Rheingold (1993:5) are the social aggregations that emerge as people interact over the internet. Such discussions or interactions are long enough to form human feelings or personal relationships in cyberspace. Virtual information communities are formed around interests ranging from hobbies to self-help issues, to scholarly and professional discourse or social networking. Based on data from a two-year study of three community networks, Fisher, Durrance and Unruh (2003) conclude that the internet has further facilitated the creation of effective information communities. It can be assumed that these virtual information communities help construct situations and contexts and are in turn constructed by situations and contexts. Research is needed to elucidate a framework to explore how this may guide the design of systems to support IB in the digital era. This creates challenges and opportunities for the information professional. The opportunity to package relevant digital information in an accessible format using a variety of channels such as websites, portals, portlets and cloud technology for example is prevalent today. The internet can be used as a platform to transmit information, data and messages using cloud computing technology. The cost of access may be passed on to users. The advantage of using Web 2.0 technology is that it can be used to create community knowledge and for activities such as storytelling and sharing experiences. Kirkland (2010:35) states that there is a need for collaboration and relationship building in the use of newer technologies.

\section{Research methodology}

The study was limited to Chinese migrants who spoke Mandarin and who had arrived in New Zealand in the period January 2009 to January 2010. Respondents who had immigrated in the last year were selected because research indicates that time spent in their new country may influence respondents' awareness of available information resources (Caidi 2008; Childers 1975; Fisher, Durance \& Hinton 2004; Shoham \& Kaufman Strauss 2008) and may also influence the type of information they need. New migrants also have a specific need for settlement information that is different to those migrants who have been living in New Zealand for more than a year. Creating a new identity, assimilating a new culture while preserving the old, succeeding in a foreign education system, acquiring a new language and developing the skills to function, work and communicate in a new society are all challenges facing new immigrants.

The method used to establish the IB of new Chinese immigrants was: a literature study and a survey using semistructured interviews. The study was cross sectional, that is, it took place at a particular point in time. A qualitative 
research methodology was used because this method was more suited to understanding the complex IB of new migrants. In the survey, data were collected by means of one-on-one in-depth interviews in order to gain an understanding of each of the respondents' IB.

A stratified sample was necessary to ensure that the sample population was as homogeneous as possible. The heterogeneous immigrant population in New Zealand was stratified according to ethnicity, language and period of time in New Zealand. The respondents were thus drawn from the target population namely New Chinese migrants who spoke Mandarin and had migrated to New Zealand in the previous twelve months. The sample was also restricted to those who had migrated under the general skills and business investor category and who live in the Auckland region. Refugees were excluded from the survey population because it was assumed that their information needs would differ from those of immigrants.

The questionnaire design was based on issues identified as important in the literature survey with regard to IB. This determined the structure of the interview. Respondents could choose either the English or Mandarin questionnaire and a translator accompanied the researcher to translate when necessary. Thirty respondents were selected to participate in the study using the snowball method. The method was chosen for a combination of reasons, the most important being that research indicates that Chinese migrants are distrustful of strangers (Schouten 1996:4; Xinhua 20II) and thus could be reluctant to participate in a study unless they were introduced to the researcher by someone they knew. Data was collected on the following areas of enquiry: profile of the new migrant including demographic information; establishing the new migrant's information seeking habits and behaviour with regard to everyday information seeking; establishing the new migrant's use of the internet and information seeking habits with regard to the internet and Mandarin language websites.

\section{Survey findings}

Respondents were interviewed in-depth about their information needs, information grounds and habits, their use of the internet for information seeking, their use of the public library and whether or not they would use a public library Mandarin language web portal for their information needs. The aim of the study was to answer the main research questions, that is, what the IB of new Chinese immigrants to New Zealand is and whether a public library portal can be used to meet these needs.

\subsection{Demographic data}

The findings relating to demographic data indicate that nine respondents were married and 21 unmarried. Sixteen respondents were between the ages 18 to 40 years and 14 respondents were over the age of 40 . Only respondents 18 years and over were interviewed due to issues of informed consent. Ages had to be estimated based on physical appearance and occupation since it is considered offensive to ask Chinese people their age.

Respondents were selected on the basis that they were new migrants that had arrived in New Zealand less than a year ago. Nearly half of the respondents had spent between nine and 12 months while only four had spent less than three months in New Zealand. The majority of the sample had thus had some time to adjust to life in New Zealand.

Respondents were asked which country they came from because Mandarin and Cantonese are spoken in a number of countries. The responses indicated that nearly two-thirds (63\%) came from Mainland China whilst the remainder came from Taiwan (20\%), Malaysia (6.7\%) and Singapore (10\%). Country of origin will play a role in languages spoken and cultural characteristics. This may influence information seeking behaviour and habits and resources required to meet new migrants' information need

\subsection{Employment}

Five of the respondents were students and a similar number were retirees. Four of the respondents were homemakers; three were unemployed and a similar number were shop assistants. Two respondents were self-employed and the same number were volunteers. The remaining respondents were a cab driver, a fast food worker, an administrator and a cashier. The relatively high percentage of unemployed (10\%) and the high percentage (20\%) of respondents forced to take lower paying jobs than they were qualified for may be the result of the current economic recession.

\subsection{Fluency in English}

New Zealand is an English speaking country where the majority of resources on the internet placed there by the New Zealand Government will be in English. It was therefore necessary to find out how fluent the respondents were in English and questions relating to this were included in the interview. Questions were included to gain an understanding of respondents' ability to read and understand English. This is important for a number of reasons:

- the inability to understand English would be a barrier to accessing vital settlement information via the internet and 
would indicate a need for this information to be available in Mandarin; and

- research indicates that for effective searching the language abilities of the user should match that of the information retrieval system (Nantel, 2008).

In response to questions relating to the ability to read and understand English, respondents commented that they frequently used a print or electronic dictionary. This would indicate that they were able to decode the text but not necessarily to understand the content. In fact, all but four respondents indicated that they could read English but that their English language skills were limited.

Table I Comprehension of written English

\begin{tabular}{lcc}
\hline Level of comprehension & Number & Percentage \\
\hline Very well & - & $-\%$ \\
Well & - & $-\%$ \\
Average & 9 & $30 \%$ \\
Not well & 17 & $56.7 \%$ \\
Not at all & 4 & $13.3 \%$ \\
Total & 30 & $100 \%$ \\
\hline
\end{tabular}

The level of English language comprehension appeared to be very basic from the responses (see Table I). Most of the respondents indicated that they were attending English language classes to improve their English.

It was noted that most respondents indicated that it was important to learn English in order to secure better paying employment and thirty per cent of the respondents had indicated they were looking to better their employment opportunities. Emigrants to New Zealand under the general skills category are required to pass an English reading, writing and comprehension test in order to satisfy immigration requirements. Although most have met the testing requirements, they still experience difficulties with English.

For those with limited English comprehension, searching databases and retrieval systems where the language used is English will be problematic. IR systems are designed on the basis that users will be able to specify their needs and obtain the results that precisely match their requests from the systems. For the respondents expressing their information needs in English would be an additional barrier to effective searching for resources where resources are presented in English.

It can be assumed that new immigrants with little or no understanding of English will encounter difficulties finding relevant information especially in their first year. This would indicate a possible role for public libraries to meet this need by making important settlement information available in Mandarin.

\subsection{Use of the internet}

All but one respondent used the internet. Frequency of internet use differed amongst older and younger respondents as well as between students, job seekers and older respondents. The internet was used by respondents for social networking, employment information, banking, on-line shopping, to read the news and to learn about local events.

Table 2 Reasons for using the internet

\begin{tabular}{|c|c|c|c|c|c|}
\hline Category & Always & Very Often & Sometimes & Rarely & Never \\
\hline \multicolumn{6}{|l|}{ To share knowledge with the world, for example } \\
\hline through a blog, email, skype and facebook. & $15(51.7 \%)$ & |4(48.3\%) & - & - & - \\
\hline To get employment information & $16(55.2 \%)$ & 13(44.8\%) & - & - & - \\
\hline To do your personal banking & $18(62.1 \%)$ & $9(31 \%)$ & $2(6.9 \%)$ & - & - \\
\hline To learn about local events & $16(55.2 \%)$ & $8(27.6 \%)$ & $5(17.2 \%)$ & - & - \\
\hline To read the news & $17(58.6 \%)$ & $4(13.8 \%)$ & $7(24.1 \%)$ & - & $\mathrm{I}(3.4 \%)$ \\
\hline To get educational material & $10(34.5 \%)$ & $6(20.7 \%)$ & $9(31 \%)$ & $2(6.9 \%)$ & $2(6.9 \%)$ \\
\hline
\end{tabular}

The percentages in the table above refer to the 29 respondents who stated that they used the internet (i.e. percentages are worked out where $\mathrm{N}=29$ ). All respondents indicated that they used the internet to get employment information. Twenty-five respondents (86\%) indicated the need to get educational material. The need to up-skill, retrain and learn English was evident in responses to open questions. One of the most important needs of new immigrants is the need for 
employment and this was reflected in the findings. The economic recession and the difficulty in finding employment added to their need for relevant job related information. The findings indicate that the context and situation of respondents influenced their IB.

Categorizing respondents into two broad age groups when discussing hobbies and pastimes and sources consulted for recreational information assisted in explaining the influence of age on IB in terms of these two aspects.

Table 3 Hobbies and pastimes of respondents ( 18 - 40 years)

\begin{tabular}{lcc}
\hline Hobbies and Pastimes & Number of responses & Frequency of use for age group \\
\hline Fashion & 8 & $50 \%$ \\
Visiting friends & 7 & $43.8 \%$ \\
Photography & 3 & $18.8 \%$ \\
Facebook/skype & 14 & $87.5 \%$ \\
Computer games & 8 & $50 \%$ \\
Fitness and beauty & 5 & $31.3 \%$ \\
Internet shopping & 6 & $37.5 \%$ \\
\hline
\end{tabular}

Younger respondents used the internet for recreational information and also made extensive use of it for social networking sites, like Facebook and Skype, to meet their need for recreational information.

Table 4 Hobbies and pastimes of respondents (40 years and older)

\begin{tabular}{lcc}
\hline Hobbies and Pastimes & Number of responses & Frequency of use for age group \\
\hline Golf & 5 & $35.7 \%$ \\
Sewing & 3 & $21.4 \%$ \\
Home decorating & 3 & $21.4 \%$ \\
Cooking & 10 & $71.4 \%$ \\
Reading on self-improvement & 2 & $14.3 \%$ \\
Scrap-booking & 5 & $35.7 \%$ \\
\hline
\end{tabular}

The answers to the question on pastimes and hobbies by the older respondents (ages 40 years and over) mentioned activities such as golf, sewing, home decorating, cooking, gardening, fishing, collecting, knitting, readings on selfimprovement, scrap-booking and so on.

All respondents indicated a need for recreational information in their home language Mandarin. This indicates that there is a need for public libraries to provide such information. All respondents used the local Chinese radio and newspaper as a source for Mandarin recreational information. Respondents were able to effectively source information in Mandarin from various sources including the internet. Respondents indicated that they had a greater need to access information relevant to their immediate survival needs rather than recreational information. Older respondents used family, friends, church or contacts in the Chinese community for social networking rather than internet based tools such as Facebook. Dervin (2005) identifies age as an important demographic factor which influences IB and this was reflected in the sources consulted to meet the recreational needs of respondents as indicated in Tables 3 and 4.

\subsection{Public library usage}

It was important to establish proximity to public libraries as research has shown that proximity to the public library is an important factor in usage (Boston Public Library 2010).

Twenty-three (76.7\%) respondents indicated that the local public library was close to where they lived and seven $(23.3 \%)$ respondents said that they did not have a public library nearby. It is possible that the creation of public library web portals to address the information needs of new migrants may alleviate the need to visit the public library in person as these sources would then be available via the internet. All the respondents were aware of the existence of public libraries and the proximity to their homes or place of work.

Most public libraries in New Zealand do not charge to use the internet except for certain services such as e-mail and the use of social networking sites. The question relating to whether the respondents knew of the free internet access to these sites at their local public library was asked to gauge respondents' familiarity with what is available at a public library 
and their willingness to use the public library and public library web pages more frequently if information was tailored to their specific needs.

Twenty $(66.7 \%)$ respondents indicated that they did know that there was no charge for accessing certain internet sites using computers available at the public library while the remaining ten $(33.3 \%)$ said that they were unaware of this. Most respondents had internet connection at home or could use the internet free at work or on campus. However, the fact that two-thirds (66.7\%) of the respondents knew that certain sites could be accessed free at the public library indicates that they used the internet at the library and were aware of these sites irrespective of access elsewhere. This indicates that offering access to a broader range of free websites may be welcomed.

However, all respondents indicated that they would make more use of the internet if public libraries collated Mandarin language resources on their websites. All respondents also indicated that information would be useful if it was provided in both English and Mandarin. The same respondents also believed that their integration into New Zealand would have been easier if they had been directed to one web site for on-line resources to assist them in their initial settlement. It can be assumed from these responses that access to information sources relevant to new migrants in Mandarin via a public library portal would be a welcome and useful source of information. New migrants can use on-line public library resources without limitation during the opening hours of the library.

\section{Conclusions and recommendations}

The findings indicate that demographic factors such as age, language, culture, employment and income played an important role in determining new immigrants' information needs and the sources of information used to meet these needs. This is similar to findings in other research such as that carried out by Dervin (2005); Hargittai (2003); Hargittai and Hinnant (2006). Respondents used a diverse range of both formal and informal resources to meet these needs.

Respondents in the study were familiar with the internet and used the internet to access resources in both English and Mandarin. An important finding of this study was that the information resources needed by new migrants were scattered and diverse and respondents often did not know where to look for the information they needed. Respondents tended to use a variety of sources to meet their needs for everyday survival information; these included both formal and informal channels for example talking to family and friends, radio, newspapers, television, and the internet. Information resources appeared to be scattered and dispersed as opposed to integrated and collated to meet the specific everyday information needs of respondents. This was evident in the provision of information by various departments to new migrants, for example Auckland Regional Migrant Services, Inland Revenue Department (IRD), Work and Income New Zealand (WINZ) and so on.

Based on this finding, it can be concluded that access to a multilingual site that collates and coordinates everyday survival information for new migrants would be useful. It is therefore recommended that New Zealand public libraries investigate this further and consider setting up such a site using freely available internet technologies such as open source software and cloud computing technology. This information, if presented on a parallel web portal in the language of migrants, will be a further advantage to the successful settlement of new emigrants.

\section{References}

Bates, M.J. 1979. Information search tactics. Journal of the American Society for Information Science, 30(4):205-2I4.

Belkin, N.J. 1980. Anomalous states of knowledge as a basis for information retrieval. The Canadian Journal of Information Science, 5 (May):33-143.

Belkin, N.J. 1990. The cognitive viewpoint in information science. Journal of Information Science, I6 (Feb): I-I5.

Belkin, N.J., Oddy, R. \& Brooks, H. 1982. ASK for information retrieval. Journal of Documentation, 38:I-7I(part I) \& I45164(part 2).

Boston Public Library. 20I0. Public use measures. [Online]. http://bpl.org/finances/BPLMeasures033I20I0.pdf Accessed on 23 January 2010.

Breeding, M. 2009. The advance of computing from the ground to the cloud. The Systems Librarian, Nov/Dec:22-25.

Caidi,N. 2008. Information practices of ethno-cultural communities. Toronto: Centre of Excellence for Research on Immigration and Settlement.

Chatman, E. A. 1985. Information, mass media and the working poor. Library and Information Science Research, 7:97-I I 3.

Chatman, E. A. 1996. The impoverished life-world of outsiders. Journal of the American Society for Information Science, 47(March): 193-206.

Chatman, E. A 1999. A theory of life in the round. Journal of the American Society for Information Science, 50:207-2 17.

Childers, T. 1975. The information poor in America. Metuchen, NJ: Scarecrow Press.

Dervin, B. 1983. An overview of sense-making research: concepts, methods and research to date. [Unpublished]. Paper presented at the international communication association annual meeting. Dallas, Texas, USA.

Dervin, B. 1992. From the mind's eye of the user: the sense-making qualitative-quantitative methodology. In: Glazier, JD. \& Powell, RR. (eds). Qualitative research in information management. Englewood, CO: Libraries Unlimited, pp. 6I-84. 
Dervin, B. 1999. Sense-making theory and practice: an overview of user interests in knowledge seeking and use. Journal of Knowledge Management, 2(2):36-46.

Dervin, B. 2005. Libraries reaching out with health information to vulnerable populations: guidance from research on information seeking and use. Medical Library Association Supplement, 93(4):74-80.

Dervin, B. \& Foreman-Wernet, L. (eds). 2003. Sense-making methodology reader: selected writings of Brenda Dervin. Cresskill, NJ: Hampton Press.

Ellis, D. 1989. A behavioural approach to information retrieval system design. Journal of Information Science, I 5:237-247.

Fisher, K.E., Durrance, J.C. \& Hinton, M.B. 2004. Information grounds and the use of need-based services by immigrants in Queens, NY: a context-based outcome evaluation approach. Journal of the American Society for Information Science and Technology, 55(8):754 - 766.

Fisher. K.E., Durrance, J.C. \& Unruh, K. T. 2003. Information communities: characteristics gleaned from studies of three online networks. ASIST. [Online]. http://ibec.ischool.washington.edu/static/pubs/asist2003.pdf. Accessed on 17 October 2010.

Hare, J. 2009. Community- led libraries: the working together project. Metropolitan libraries conference. May I2, 2009. Brisbane. [Online]. http://www.ifla.org/files/metropolitan-libraries/conferences/Hare\%20IFLA.pdf. Accessed on 09 August 2010.

Hargittai, E. 2003. The digital divide and what to do about it. In: Jones, D. C. (ed.) New economy handbook. San Diego, CA: Academic Press, pp. 822-84I.

Hargittai, E. \& Hinnant, A.. 2006. Towards a social framework for information seeking. In: Spink, A. \& Cole, C. New directions in human information behaviour. Netherlands: Springer, pp. 55-70.

Ingwersen, P. 1992. Information retrieval interaction. London: Taylor Graham.

Ingwersen, P. 1996. Cognitive perspective of information retrieval interaction: elements of a cognitive IR theory. Journal of Documentation, 52(I):3-50.

Kirkland, A.B. 20 I 0. Clearing the fog about the cloud: some relationship advice. School Libraries in Canada, 28(3);33-35.

Kuhlthau, C.C. 1993. A principle of uncertainty for information seeking. Journal of Documentation, 49(4):339-355.

Kuhlthau, C.C. 2005. Kuhlthau's information search process. In: Fisher, K. E., Erdelez, S. \& McKechnie, L. (eds). Theories of Information Behaviour. Medford, N.J.: ASIS\&T:230 - 234.

LIANZA. 2006. Public libraries of New Zealand: a strategic framework 2005 to 20I5: consultation document. [Unpublished document].

Lievrouw, L.A. 200I. New media and the "pluralisation of life-worlds". New media \& society, 3(I):7-28.

Lo Bianco, N., Cunningham, A. \& McCombe, C. 2010. New communities, emerging content: digital inclusion for minority language groups. Victoria, Australia: Vicnet, State Library of Victoria.

Mack, N., Woodsong, C., MacQueen, K.M., Guest, G. \& Namey, E. 2005. Qualitative research methods: a data collector's field guide. Family health international. [Online]. http://www.fhi.org. Accessed on 25 October 2010.

Meyer, H.W.J. 2009. The influence of information behaviour on information sharing across cultural boundaries in developed contexts. Information Research, 14(I):paper 393.[Online]. http://informationr.net/ir/I0-2/paper393.html. Accessed on I6 October 2010.

Nantel, J. 2008. The impact of language and culture on website usability. www.chairerbc.com/axisdocument.aspx. [Online]. Accessed on 4 October 2010.

Papillon, M. 2002. Immigration, diversity and social inclusion in Canada's cities. Ottawa: Canadian Policy Research Networks.

Pettigrew, K.E. 1998. The role of community health nurses in providing information and referral to the elderly: a study based on social network theory. University of Western Ontario: Ontario.

Pettigrew, K.E. 1999. Waiting for chiropody: contextual results from an ethnographic study of the information behaviour among attendees at community clinics. Information Processing and Management, 35(6):80I - 817.

Pettigrew, K.E. 2000. Lay information provision in community settings: how community health nurses disseminate human services information to the elderly. Library Quarterly, 70(I):47 - 85.

Rheingold, H. 1993. The virtual community: homesteading on the electronic frontier. Wesley Reading: MA.

Schouten, H. 1996. Study finds many Asians not mixing with NZ society. Dominion Post:4.

Shoham, S. \& Kaufman Strauss, S. 2008. Immigrations' information needs: their role in the absorption process. Information research, I3(4):paper 359.[Online]. http://informationr.net/ir/I3-4/paper359.html. Accessed on I3 October 2010.

Statistics New Zealand. 2010. New Zealand's official statistics agency. [Online]. http://www.stats.govt.nz. Accessed on 23 May 2010.

Srinivasen, R. \& Pyati, A. 2007. Diasporic information environments: re-framing information behaviour research. Journal of the American Society of Information Science and Technology, 58(I 2): I 743 - 1744.

Thorhauge, J. 2010. Digital libraries for all: a discussion on strategic development. Danish agency for libraries and media. [Online]. http://www.bibliotekogmedier.dk/fileadmin/user_upload/dokumenter/om_os/Direktoeren/Taler_og_praesentationer/ Digital_libraries_for_all._Paper. Accessed on 10 January 2010.

Tuominen, K. \& Savolainen, R. 1997. A social constructionist approach to the study of information use as diverse action. London: Graham Taylor.

Wilson, T.D. 1999. Models in information behaviour research. Journal of Documentation, 55(3):249-270.

Xinhua. 20II. Roundup: media coverage slants New Zealand attitudes to Asians. China Daily. [Online]. http:// www.chinadaily.com.cn/xinhua/20I I-04-I2/content_2278333.html. Accessed on I7 June 201 I.

SA JnI Libs \& Info Sci 2012, 78(I) 